\title{
Research and Application of Special Control Procedure Management for Construction Safety
}

\author{
Jinhui $\mathrm{Li}^{1}$, Minmin Yuan ${ }^{2 *}$ and Xiaodong Shang ${ }^{2}$ \\ ${ }^{1}$ Huang Mao Hai Link Management Center, Zhuhai, Guangdong Province, 519055, China \\ ${ }^{2}$ Research Institute of Highway, Ministry of Transport, Beijing 100088, China
}

\begin{abstract}
A very important factor in production safety accidents caused by engineering construction is that the approved plan has not been effectively implemented. Therefore, cracking the plan and implementing the two-skin is an important issue for engineering construction safety management to be solved urgently. This article takes the construction of the NanSha Bridge as a case, and for the more dangerous sub-projects, the premise is to ensure the construction period, quality, safety and environmental protection goals, and meet the basic requirements of norms, safety, environmental protection, and soil and water conservation. The risk should be systematically assessed, and targeted avoidance and preventive measures should be formulated, and the definition and characteristics of the special control process acceptance management method and the control points and processes in the implementation process should be studied. Using special control process management, the NanSha Bridge adopts special control process acceptance management procedures for dangerous sub-projects, which solves the problem of process acceptance or safety inspection and acceptance. In the past, only the quality inspection department or safety department personnel participated. The shortcomings of inspection or acceptance require that the main control focus of each special control process inspection is consistent with the actual project. Through the special control process acceptance work, the hidden dangers can be found in advance and rectified and eliminated in time before the next step of construction. The hidden dangers are truly eliminated in the bud and the consistency between the approved plan and the actual implementation can be effectively guaranteed. Through special control process management, the dangerous sub-item project plan is truly implemented, avoiding the phenomenon of two skins in the approval plan and implementation, which has high reference significance for similar projects.
\end{abstract}

\section{Introduction}

Throughout the domestic production safety accidents, many of them are caused by the disconnection between the actual construction on site and the scheme, that is, the implementation of the scheme is not strictly followed [1,2]. How to ensure the strict implementation of the approved scheme is an important issue facing every engineering technical and management personnel.

The NiZhou water road bridge adopts a main span of $1688 \mathrm{~m}$, a double tower and a double span suspension bridge (the length of the main bridge is $548+1688 \mathrm{~m}$ ). The main tower is 260 meters high and is the world's largest span steel box girder suspension bridge [3,4]. The DaShaishui Bridge adopts the main span of $1200 \mathrm{~m}$ double-tower single-span suspension bridge, the main tower is 193.1 meters high; the approach bridge mainly adopts $39 \mathrm{~m} \sim 62.5 \mathrm{~m}$ span restressed concrete segment assembly bridge. The three interconnections are mainly cast-in-place, suspended casting and precast small box girders.

The Nansha bridge project involves partial construction method, and the vast majority of the solutions are in greater danger division component project, the contractor in the preparation of special solution can basically to ensure time limit for a project, the premise of quality, safety and environmental protection objectives and meet the specification, safety, environmental protection, the basic requirements, such as soil and water conservation system evaluation was carried out on the possible risk, and formulate the pertinence of evade, preventive measures [5-8]. From the management of similar projects, there are often "two skins" phenomenon in the construction site that the implementation plan can not be fully implemented in accordance with the approval plan. But in the process of implementing the special scheme of Nansha bridge project, we should explore the method of control process management, control process acceptance management scheme, and solve the problem of approval plan and implementation of "two skins".

\footnotetext{
*Corresponding author's e-mail: mm.yuan@rioh.cn
} 


\section{Definition and characteristics of special control process acceptance}

\subsection{Definition of special control process acceptance}

To strengthen the security of greater danger engineering controls, Nansha bridge project in greater danger of construction trestle and platform, cast-in-place beam support, climbing form, settled and rolling over, the hanging basket construction, installation and across, and dismantling of tower crane foundation, cable crane and steel box girder hoisting installation and removal, catwalks focus on examination of construction process control procedures, as a control process, according to the process acceptance procedures contractor reinspect selfchecking and supervision units.

\subsection{Characteristics of special control process acceptance method}

For the construction procedure included in the special control procedure, the head of relevant departments of the contractor shall conduct self-inspection. After the technical head of the project and the deputy manager of safety production confirm the qualification, the contractor shall fill in the Acceptance Form of Special Control Procedure and submit it to the supervisor. After the on-site inspection, the supervisor shall sign the approval before proceeding to the next procedure. If the supervisor fails to pass the acceptance inspection on the site, the rectification notice shall be opened on the site, and the special control process acceptance shall be applied again after the rectification is passed. The resident supervision engineer and safety supervision engineer shall not sign the Approval Form of Procedure Inspection Application if the process inspection is unqualified.

Compared to previous process acceptance or security check acceptance, main characteristic is that the inspectors shall be at the construction control working procedure and supervision units each related personnel to participate in, more to strengthen the safety conditions of acceptance veto control requirements, such as different only quality inspection department or security department personnel to participate in the inspection or acceptance. The special control process management method also truly achieves the modern safety management concept such as "production must be managed safely" and "one post with double responsibility and each post with responsibility".

\section{Control the main control points of process acceptance}

In the process of the Nansha bridge specifically charged management, for high piers rolling over and settled tower climbing form construction, installation and suspension pouring hole, hanging basket, support cast-in-place beam, pier platform, tower crane foundation, strand, cable crane installation and dismantling, steel box girder hoisting, cable saddle door frame installation and removal, cat, erect and dismantle key construction process are listed as the exclusive control of working procedure. For each control procedure, formulated the corresponding check acceptance form, and mainly discusses the special solution preparation of examination and approval, technical clarification and personnel education, safety protection, mechanical equipment, quality of temporary electricity utilization, the structure of the facilities in each control procedure checklist has different priorities reflect, namely for each control process characteristics of the professional category, formulate corresponding examination project, the purpose is to maximum extent, to do the main control working procedure inspection control emphases in conformity with the engineering practice, to achieve targeted and operability of examination and acceptance.

For supervisors in terms of acceptance control process control point, has been clear about the professional supervision engineer on the basis of the construction unit self-check, found hidden dangers to the safety of structures, the corrective notice must be issued, after rectification is completed to fill in the corrective reply form, after the acceptance of reorganizing, can control process acceptance notification supervision; On the basis of the self-inspection by the construction unit, if the professional supervision engineer finds any hidden danger that does not endanger the structural safety, such as insufficient border protection, he shall directly sign the opinions on the inspection sheet of the specially controlled process. After the rectification, the supervision project shall directly sign the review opinions on the inspection sheet of the specially controlled process.

\section{Implementation Steps}

Control process acceptance at the scene of the construction process by the construction units first selfcheck, head of the organization, qualified after fill in the table of the control process acceptance supervision, supervision (resident supervision engineer or security supervisor, specific prescribed by site supervision) after the on-site inspection qualified sign recognition, the table as the process inspection application approval form attachments. The supervisor safety engineer of the supervision unit shall sign the Approval Form for Process Inspection application at the same time. It is strictly prohibited to put into use without verification or unqualified after verification. If there is any violation, the supervision unit shall immediately issue the order to suspend construction and punish, and report to the project owner in time.

The acceptance procedure of Nansha bridge special control process is shown in Figure 1. 


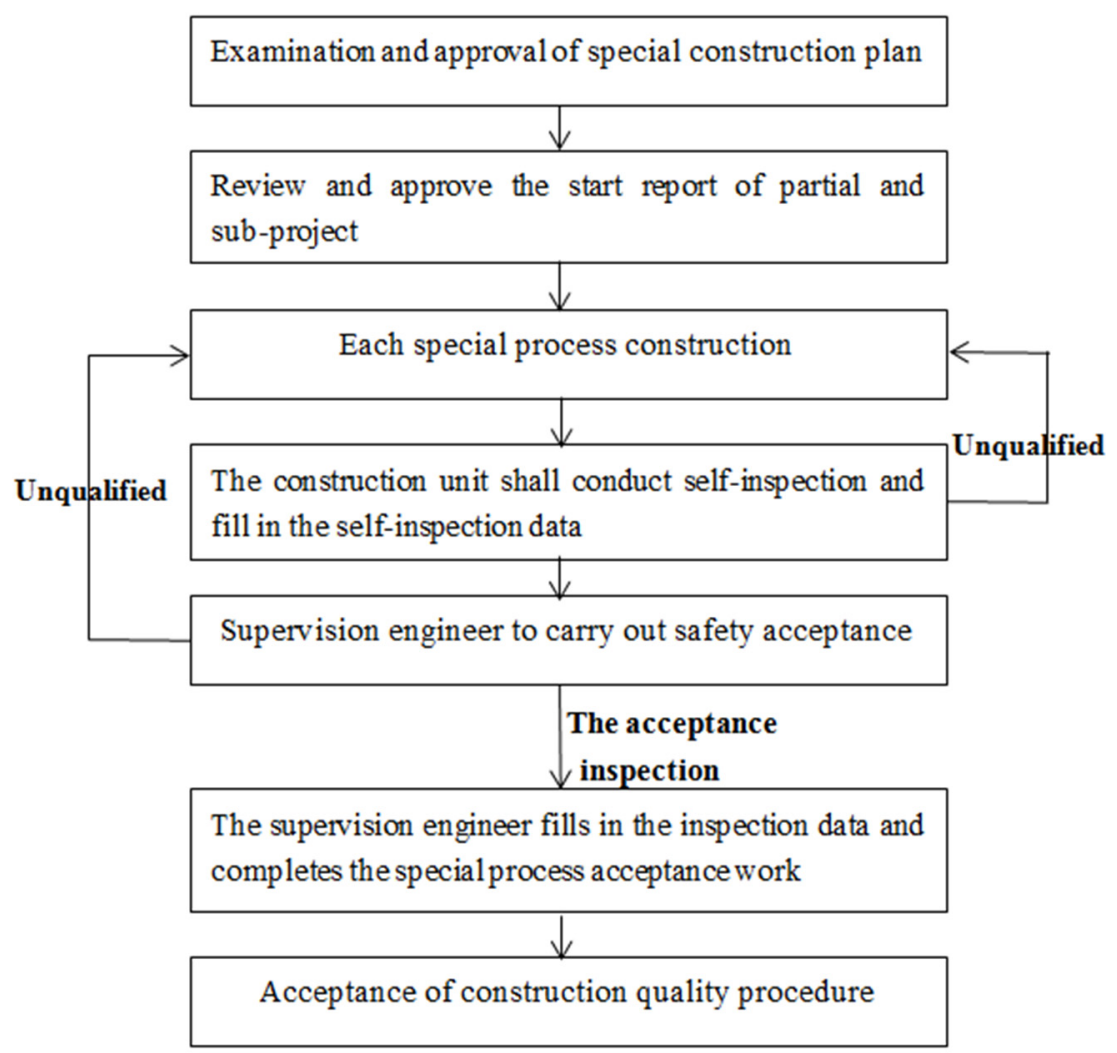

Fig 1. Special Control Process Acceptance Procedure

The specific implementation procedures of the specially controlled process acceptance management are as follows:

- The first article inspection and acceptance by the construction unit technology, head of the organization department, machine, material, quality inspection departments self-check, measurement testing and other departments to control process and monitoring, after the first article inspection control process of acceptance by the on-site technical organization, head of the technical department, machine, material, quality inspection departments, measurement testing departments participate in the acceptance, to ensure the process construction meet the provisions of the technical and safety requirements.

- Each control process is completed, the professional supervision engineer on-site acceptance of receiving the application for construction units, construction units submit corresponding self-check, the professional supervision engineer after the acceptance of the next working procedure, unqualified does not allow for the process, found that there is a big risk factors such as acceptance of the process, the professional supervision engineer on site to open the rectification notice, request the rectification within a time limit, at the same time do a good job records, rework or fill in the corrective reply form, after rectification after the acceptance of reorganizing, sign the acceptance form control process to continue the process of construction.

- The rectification situation includes the rectification of the on-site entity, the rectification of the disclosure training and the education of the responsible person; After cause analysis, all responsible persons are required to sign; If there are no risk factors in the acceptance results, the Rectification Notice may not be opened, and the re-examination and verification work shall be undertaken by the safety management department of the construction unit and the on-site supervision institution.

- When the supervision engineer examines the application for handover of each dangerous part and sub-item, he should check the safety acceptance data of the special control process at the same time. If there is no safety acceptance data, the handover certificate shall not be issued and the relevant part and sub-item works shall not be measured.

\section{Implementation Effect}

Acceptance of Nansha bridge project control process management approach in the Nansha bridge project management manual, Guangdong province highway engineering construction safety standardization guide control process requirements, on the basis of the use of the exclusive control of working procedure table further refinement, increased the plate type pier double mode control work procedure table, the table and the upper suspension bridge construction control in the table clear control process is not only security management, each department personnel need to be involved, a fine item directly to specific department is responsible for, and 
precisely control procedure for site construction personnel to organize the implementation of department, security department personnel to participate in and supervise the implementation. Therefore, the execution strength and effect of special control process inspection and acceptance have been improved unprecedentedly.

The special control procedure acceptance has prompted the construction unit to change up to eight times according to the actual situation on the site and submit for approval to modify and optimize part of the special construction plan, so as to achieve the maximum consistency between the approved modified and optimized scheme and the on-site implementation, and thus to successfully pass the special control procedure acceptance and enter into the next construction. Acceptance work at the same time, through the control process, to find the hidden problems in advance, and in time before the next step of construction shall be corrected to eliminate and really the problem of hidden dangers in the bud, achieved the effect of active control in advance.

\section{Conclusion}

In recent years, the state has vigorously advocated the development of building industrialization and prefab construction. Through the development of building prefabrication, industrialization and factory, the construction quality of projects can be improved, the cost can be reduced and the workload of site construction can be reduced. Reinforcement engineering "part" construction, is to project site construction steel bar connection and binding sites of the construction of the reinforced precast processing workshops in the finish, "reinforcing cage", "steel" and the irregular reinforced part of prefabricated forming, and then lifting to construction operation complete connection between the steel part, it can greatly shorten the time for the homework, reduce the production and employment, improve the quality of construction. Taper sleeve lock reinforced joint technology's own characteristics and advantages of efficient implementation of reinforced high strength connection between product, effectively promoted the reinforced part construction accelerated development, makes the steel parts are to be applied, as surging in the field of bridge reinforcement engineering of a revolution, promote the bridge reinforcement project construction methods and construction technology of big changes, is bound to lead the future world bridge construction technology on a higher step! Through the process of management control, the management is more effectively promoted to implement in strict accordance with the approval plan, and the more dangerous divisional and subdivisional project schemes are truly implemented to avoid the "two skin" phenomenon. It is a powerful tool for Nansha bridge to achieve the two safety objectives.

\section{References}

1. An, J.W., An, X., Wang L.K. (2017) Research on Evaluation of Emergency Plan for Production Safety Accidents based on Hesitation and
Fuzziness. China Work Safety Science and Technology.,13:128-133.

2. Li, X.D., Chen, Q. (2012) Main Types and Preventive Measures of Construction Safety Accidents in China. Journal of Civil Engineering., 45:245-248.

3. Zhang, X.M., Xu, Y.Q., Lu L.T. (2019) Research on Longitudinal Restraint System of Nizhou Waterway of Humen No.2 Bridge. Bridge Construction., 49:7-12.

4. Zhu, Z.B. (2016) Construction Monitoring Technology for Foundation Pit of West Anchorage of Nizhou Waterway Bridge of Humen No.2 bridge. Bridge Construction., 5:6-11.

5. Ya, G.,Han, D.D., Shi H.Y. (2017) Study on Stability of Gravity Anchorage Foundation of Nizhou Waterway Bridge of Humen No.2 Bridge. Highway., 4:129-135.

6. Cui G., Zhou, H.X., Li L. (2017) Research and Application of Hydrophobic Pore Plug on Concrete Performance. New Building Materials., 11:28-31.

7. Wu, Y.G. (2017) Understanding and Practice of Building Sustainable Bridge Engineering. Highway., 62:98-105.

8. He, T., Luo, C.Y., Wang, X.J. (2016) Technology and Application of Collaborative Improvement of Crack Resistance and Durability of Fair Faced Concrete for High Towers. Journal of Wuhan University of Technology., 38:18-25. 